\title{
APRESENTAÇÃO DO DOSSIÊ FESTAS, ESPETÁCULOS E PATRIMÔNIOS
}

\section{FOREWORD TO DOSSIER ON FESTIVALS, SHOWS AND HERITAGE}

\author{
Luciana Chianca (UFPB)* \\ Ulisses Neves Rafael (UFS) ${ }^{* *}$
}

As temáticas reunidas neste dossiê, intitulado Festas, Espetáculos e Patrimônios, têm sido objeto de redobrado interesse intelectual ao longo dos tempos e vêm provocando estimulantes reflexões nas Ciências Sociais, área na qual se incluem nossos colaboradores nesta edição, que propõe a análise da festa a partir de duas articulações e dispositivos mais acionados contemporaneamente: os espetáculos e os patrimônios.

Um dos indícios da longevidade desse interesse é a sua presença recorrente em nossa teoria clássica, na qual destacamos aqui quatro autores: James Frazer (1854-1941), Émile Durkheim (1858-1917), Marcel Mauss (1872-1950) e Edmund Leach (1910-1989), com suas colaborações seminais ao estudo das festas, as quais vão amparar as análises subsequentes, como aquelas de Victor Turner (1974), Roberto DaMatta (1983 ), Max Gluckman ( 2010) e Jean Duvignaud (1983).

Na obra O ramo de ouro, de 1898, o pioneiro James Frazer sugere uma original análise de práticas rituais e comportamentos simbólicos a partir do tema do deus imolado. Seu culto remeteria às formas primordiais do pensamento humano, de cujo arcaísmo seria possível reconstituir toda a evolução das nossas formas espirituais. Sob este aspecto, as cerimônias eram vistas por ele como manifestações privilegiadas para a recriação, assumidamente imaginativa, desse desenvolvimento e de sua unidade essencial.

O viés evolucionista de Frazer (1982) será doravante substituído pelo interesse na compreensão da sociedade como um todo e pelos modos como ela toma consciência de si e se renova. Revigorando o interesse pelas cerimônias enquanto importante operador simbólico, Émile Durkheim empresta atenção considerável aos ritos, enquanto manifestações práticas

\footnotetext{
* Doutora em Antropologia pela Université Bordeaux II (França). Professora Associada do Departamento de Ciências Sociais e do Programa de Pós-Graduação em Antropologia da Universidade Federal da Paraíba. E-mail: lucianachiancaufpb@yahoo.com.br

${ }^{* *}$ Doutor em Sociologia e Antropologia pela Universidade Federal do Rio de Janeiro (2004). Professor Associado IV do Departamento de Ciências Sociais e do Programa de Pós-Graduação em Antropologia da Universidade Federal de Sergipe. E-mail: ulisses38@gmail.com
} 
das imagens e representações sobre o mundo e construídas pelos homens. Sob este aspecto, na obra As formas elementares da vida religiosa (1996) as festas recebem suas primeiras referências específicas em textos socioantropológicos, sendo definida a partir do conceito de ritual. Para Durkheim, a vida ritual poderia ser dividida em duas principais formas de culto que marcariam a relação dos indivíduos com o sagrado e com o profano, ambivalência que constitui o ponto de convergência da vida coletiva.

Enquanto a vida social e religiosa se dividiria nos polos do sagrado e do profano, os homens organizariam diferentes formas de relacionamento com esse sagrado. Por um lado, teríamos os cultos de natureza negativa, marcado pela manutenção da distância com a esfera do sagrado (através de sacrifícios, por exemplo), e cultos de natureza positiva, sendo as festas o seu paradigma, pois através delas reviveríamos também nossos mitos coletivos.

Para Durkheim, as festas expressam a experiência religiosa do homem por um "estado de efervescência, às vezes até de delírio, que não deixa de ter parentesco com o estado religioso. $O$ homem é transportado fora de si, distraído de suas ocupações e preocupações ordinárias. Por isso, observam-se em ambos os casos as mesmas manifestações: gritos, cantos, música, movimentos violentos, danças, busca de estimulantes que elevem o nível vital”. (1996, p. 417-418) Além de revigorar o indivíduo, a festa também desperta o seu sentimento de vínculo coletivo, por isso "o rito, portanto, só serve e só pode servir para manter a vitalidade das crenças, para impedir que elas se apaguem das memórias, ou seja, em suma,, para revivificar os elementos mais essenciais da consciência coletiva".(1996, p. 409)

Inconscientes da função social do rito, todos dançam, cantam e participam das festas movidos pela alegria: o caráter recreativo e estético ganha importância na teoria durkheimiana por sua força performática, pois faz os “ homens esquecerem o mundo real, transportando-os a um outro em que sua imaginação está mais à vontade" (1996, p. 414). Entre o cerimonial religioso e a comemoração estética a diferença está "na proporção desigual segundo a qual estes dois elementos se combinam." (1996, p. 418). Ainda para ele, o estético e o religioso estariam tão próximos que seus "participantes passam de um gênero a outro sem solução de continuidade" (1996, p. 414), pois se o cerimonial remete a um passado mítico e coletivo, o elemento estético é importante na dimensão de transporte do indivíduo. Assim, ambos são necessários, pois a festa recria o indivíduo e a sociedade através dela própria. No entanto, quando o riso se torna mera recreação e se esvai seu conteúdo, o ritual perde seu sentido: é quando se "afrouxa o vínculo entre a história da tribo e os acontecimentos e personagens representados" (1996, p. 414). Este processo conduziria progressivamente a sociedade ao "domínio da pura fantasia" (1996, p. 414) levando ao "corroborie vulgar, simples regozijo público que nada mais tem de religioso e do qual todos podem indiferentemente participar" (1996, p. 414-415).

Os reflexos do pensamento durkheimiano se fazem notar no seu discípulo mais imediato, Marcel Mauss, que no Ensaio sobre a dádiva (1974), entre outros temas, dedica-se, sobremaneira, ao potlatch, à festa perpétua, considerada a forma mais evoluída de prestação total, onde estão 
envolvidas pessoas morais trocando e destruindo ostensivamente bens e riquezas acumulados. Roberto Hertz (1881-1915) também integra essa tradição intelectual francesa, embora sua contribuição tenha sido interrompida muito precocemente em decorrência de sua participação na Primeira Grande Guerra. Seu artigo sobre a festa de São Besso, evento religioso dos Alpes italianos e publicado em 1913, apesar de não ser seu trabalho mais conhecido, tem servido de suporte para vários estudiosos das festas de santos católicos.

Nas gerações sucessivas de estudiosos franceses, contudo, a festa perde seu lirismo: autores como Roger Caillois (2015), Georges Bataille (2013) e, posteriormente, Jean Duvignaud (1983) trazem à análise da festa seu paroxismo, seu abrasamento limitado e sua destruição consertada. Esse enfoque marginal, por assim dizer, destitui da festa seu caráter utilitário e racionalista, comum em reflexões da época. Ou seja, na contramão dos estudos realizados no período que permeia a Segunda Grande Guerra, e até mais recentemente, a partir daquilo que Baudrillard (1992) chamou de "processo de reversão", a ênfase recai sobre o aspecto aparentemente inútil da festa, ou no mínimo, seu exacerbamento e gratuidade.

Enquanto permanece associada ao ritual, a antropologia da festa encontra longevidade, embora devamos lembrar que apesar de aproximados na teoria das representações coletivas durkheimiana, ritual e festa não são sinônimos: se toda festa pode ser considerada um ritual (nos moldes clássicos de suspensão temporária dos papéis sociais ou reforço da condição cotidiana), nem todo ritual é uma festa.

Outra importante abordagem da festa relaciona intimamente os dois conceitos: festa e ritual, e é tributária da tradição inglesa, onde Edmund Leach (1978) desvendou o aspecto comunicacional da cultura, que para ele é essencialmente troca simbólica. Festas e rituais são exemplos de comportamentos sociais codificados que exigiriam decifração do seu sistema simbólico, pois significam sempre algo além do que representam: "os participantes de um ritual estão trocando experiências comunicativas, simultaneamente, através de vários canais sensoriais diferentes; eles estão representando uma sequencia ordenada de fatos metafóricos dentro de um espaço territorial que foi, ele próprio, organizado para fornecer um contexto metafórico à execução." (1978, p. 51).

Muito compartilhada pelos pesquisadores contemporâneos, essa visão dos rituais e festas chama a atenção para seus conteúdos, tomados como significantes que expressam a estrutura social em que se manifestam. Constituída sobre polos opostos (formalidade e informalidade, respeito e descontração, por exemplo), a festa possibilitaria ao indivíduo uma organização simbólica do mundo, lhe sugerindo um papel nesta mise-en-scene. O ritual articularia àquele ao coletivo, reorganizando num só tempo as variadas versões das estruturas simbólicas do social e recombinando seus aspectos conflitantes.

É no rastro desta tradição britânica de estudos de rituais, definitivamente consagrados por Victor Turner (1920-1983), a partir do final dos anos 1950, que a festa chega ao Brasil como tema sociológico, mais especificamente a partir da obra Carnavais, Malandros e Heróis ( 1983) 
de Roberto DaMatta. Isso não significa dizer que foi a primeira vez que a temática foi tratada no país, pois a festa é conteúdo caro à reflexões antigas e recentes no campo acadêmico nacional, cujo passado remonta a trabalhos aclamados, especialmente em torno do folclore, e realizados por expoentes fundadores do pensamento social brasileiro, como Melo Morais Filho (18441919) e Mário de Andrade (1893-1945).

Com Roberto DaMatta, porém, as festas brasileiras recebem uma análise original, sustentada por uma "sociologia do dilema brasileiro" que retoma a análise ritual de V. Turner. DaMatta estabelece três formas básicas de ritualizações da sociedade representada por três momentos festivos bastante peculiares: os carnavais, as paradas militares e as procissões. A análise do modo como cada um desses ritos comemorativos se manifesta permite-nos compreender não apenas o significado social das cerimônias em questão (o conjunto de valores da cultura no interior da qual elas se desenvolvem), como também os mecanismos fundamentais através dos quais a sociedade brasileira se deixa representar. Para ele, os rituais seriam caminhos para compreender como " elementos triviais do mundo social podem ser deslocados e, assim, transformados em símbolos que, em certos contextos, permitem engendrar um momento especial ou extraordinário" (1983, p. 61). articulando, extraordinariamente e de forma diferenciada, os elementos e relações cotidianas". Isto porque nos rituais "as coisas do mundo adquirem um sentido diferente e podem exprimir mais que aquilo que exprimem no seu contexto normal. “ (1983, p. 61)

Chegamos juntos à principal oposição da festa: o cotidiano. Marcado pela repetição e monotonia, este tem temporalidade e espacialidade repetitivas e maçantes, enquanto a festa é criativa e fértil. Dissimulando sua utilidade, o tempo da "não produção", é tempo necessário aos deuses, mas também aos homens- como bem nos alertou Durkheim. Associada aos demais domínios da sociedade, a festa pode constituir vias de acesso originais e muito reveladoras sobre seu funcionamento e dinâmica, e sua multiplicidade de formas são indícios de sua vitalidade expressiva: temos festas espetaculares, políticas, populares, privativas, públicas, de massas, urbanas, rurais, oficiais e tantas outras. Cada uma delas merece um tratamento teórico e metodológico próprio, segundo a especificidade de seu contexto, as condições da produção do campo de observação, a fortuna crítica de que dispõe e a experiência teórico-metodológica do autor da reflexão.

Hoje, no Brasil, as festas e os rituais ocupam lugar de destaque nos debates acadêmicos, mesmo se ultimamente as reflexões a seu respeito tenham sido bastante absorvidas pelo tema do patrimônio e patrimonialização, da espetacularização e da sua mercantilização crescentes. Essa é razão pela qual nosso dossiê sugeriu a sua abordagem no cruzamento desses dois recortes.

Eivadas da prudência e precação sugeridas por José Reginaldo Gonçalves, Maria Laura V. de Castro, Antonio Augusto Arantes, Regina Abreu, Maria Cecilia Londres Fonseca, entre outros autores brasileiros contemporâneos, as festas, como patrimônios imateriais, sujeitas ou não a processos de espetacularização, vêm recebendo provocantes formulações quanto ao manejo de 
tais categorias por parte de pesquisadores e seus interlocutores - sobretudo considerando as divergências observadas em contextos etnográficos assimétricos-, como os que conheceremos nos artigos aqui apresentados.

Por isso, este dossiê tem a finalidade de reforçar a reflexão acerca de questões relativas às dinâmicas contemporâneas em torno da festa e de outros rituais, conhecimentos e tradições populares, remetendo a seus processos contemporâneos e contíguos de espetacularização e patrimonialização, duas vias contemporâneas que não são compreendidas como possibilidades excludentes, uma "apocalíptica", a outra "resistente", uma destruidora, outra conservadora. Antes, são possibilidades de afirmação e ressignificação de símbolos e identidades coletivas, alternativas de consolidação e embates em torno de afirmações de direitos, territórios e memórias.

Enquanto desdobramento de uma rede de pesquisa atuante nas reuniões nacionais e regionais de Ciências Sociais, Sociologia e Antropologia, presente em diversos fóruns há mais de 15 anos, este dossiê reúne pesquisadores de importância nacional como Maria Laura Viveiros de Castro (UFRJ) e outras contribuições igualmente relevantes de autores da Universidade Federal de Pernambuco (UFPE), Universidade Federal do Oeste do Pará (UFOPA), Universidade Federal de Sergipe (UFS) Universidade Federal do Rio Grande do Norte (UFRN), Universidade Federal da Bahia (UFBA) e da Universidade Federal da Paraíba (UFPB).

Nosso dossiê visa proporcionar a interlocução e a circulação de conhecimentos obtidos a partir de práticas investigativas no campo de observação direta, construindo uma visão contemporânea deste debate, tanto do ponto de vista teórico-conceitual, quanto político-social, considerando o potencial transformador de ações incidentes sobre conhecimento tradicionais, padrões duradouros de relações de gênero e trabalho, sistemas morais e direitos peculiares, entre outros.

Sob este aspecto, o eixo das reflexões aqui reunidas volta-se para a discussão acerca do uso e da pertinência de certas categorias sociológicas, como, por exemplo, a aplicabilidade, na atualidade, de termos como folclore e cultura popular, bem como sua substituição por expressões correlatas e diversas como patrimônio imaterial ou intangível, performance e consumo cultural. Aliado às reflexões de cunho mais conceitual e sem descuidar do arcabouço bibliográfico que encobre a variedade temática das expressões culturais festivas, os integrantes deste dossiê têm em comum o fato de, num diálogo com suas respectivas perspectivas analíticas, realizarem, sob o ponto de vista etnográfico, profundas descrições e interpretações acerca das chamadas tradições populares festivas e seus desdobramentos em contextos culturais urbanos, os quais possibilitam discutir antigas questões epistemológicas.

Trata-se, portanto, de refletir sobre a profícua relação entre as festas, a patrimonialização e a espetacularização de elementos recorrentemente identificados no universo das culturas populares e do folclore, sobre a ritualização das relações entre diferentes interlocutores (Estado, grupos formais e informais, indivíduos) no campo da ação cotidiana e das políticas públicas de cultura, assim como sobre a performatização e a organização de grupos e populações num 
campo marcado por ambivalências e contradições sintetizadas em expressões locais, tradicionais, nacionais, globais, populares, mercadológicas, comerciais, digitais ou espetaculares.

Nosso Dossiê é aberto com o seminal artigo Bumba meu boi, Boi-Bumbá: a inventividade das tradições populares, da lavra da professora Maria Laura Cavalcanti, cuja trajetória intelectual e produção bibliográfica figuraria facilmente no panorama esboçado acima, não fosse a especificidade da apresentação que o texto incluído neste dossiê exige. Enfatizando a dimensão artística e espetacular das expressões populares e seu entrelaçamento performático com personagens do imaginário mítico indígena e caboclo, Cavalcanti realiza aqui um profícuo diálogo entre os bois da festa/espetáculo do Festival do Parintins e a generosa descrição de Mario de Andrade, na obra As Danças Dramáticas do Brasil.

Ela destaca duas percepções opostas sobre as danças dramáticas que exprimiriam uma oscilação presente na obra de Mário de Andrade: uma primeira visão mais fragmentária, compreendendo "as danças populares como autos onde a composição popular rechearia o núcleo básico com temas apostos oriundos de outras fontes de inspiração que nele se grudam, e que por vezes não têm ligação nenhuma com o núcleo". Uma segunda visão é mais integrada, e sugere uma construção totalizante reunindo uma composição tripartite da cultura nacional, aproximando-se assim de "um conteúdo fixo nacionalizante" em que brancos, negros e índios comporiam um mosaico cultural. Na trilha dessa ambivalência que ela identifica como marcante na obra deste pensador, encontramos uma perspectiva positiva, que destaca o aspecto original e criativo da cultura popular. Outra é habitada por um sentimento de decadência, perda, e um certo "desalento", nas palavras da autora.

Seguindo o Festival dos Bois-Bumbás de Parintins, Maria Laura convida o Boi de Mário de Andrade para uma dança, a fim de fazer ressurgir "das cinzas da desalentada sentença de morte proferida" por ele, uma coreografia com núcleo temático claro ao leitor, embora no bailado deste diálogo se destaque a versatilidade e "a afirmação da capacidade inventiva da cultura popular".

Ainda no diálogo com Mário de Andrade e a obra Danças Dramáticas no Brasil, o artigo Bailados indígenas no Carnaval: "passado adormecido" ou presente desperto?, de Luciana Chianca e Jessyca Marins, parte da presença contemporânea das Tribos indígenas no Carnaval urbano da cidade de João Pessoa-PB, interrogando-se sobre a representação performática do indígena nessa festa, onde eles são uma presença constante, não como tema de fantasias individuais, mas como grupos constituídos em torno de vestimentas, danças, coreografias, declamações, instrumentos e músicas. $\mathrm{O}$ foco do artigo é este índio encenado, representado como elemento étnico nativo e original no Carnaval urbano da cidade, desde pelo menos o ano de 1929 - data fixada pelo registro do diário da visita que Mário de Andrade fez à João Pessoa. A partir de então, breves referências à imagem do indígena no Carnaval local se sucedem na literatura folclórica e etnográfica, sendo que alguns sociólogos e cronistas chegam a descrevê-lo buscando tecer suas próprias elaborações sobre as formas e sentidos dessa expressão. Numa pesquisa apoiada sobre documentos fílmicos, fotográficos e bibliográficos dialogados com um campo contemporâneo, 
os contornos dessa performática representação do indígena são reconhecidos em outras fontes históricas do Carnaval brasileiro, onde Cucumbis, Cabocolinhos e Tribos indígenas marcam presença em diversas celebrações registradas no país.

Considerado na performance contemporânea como personagem nacional nativo, o índio é reconhecido por sua coragem e por seu poder belicoso, elementos morais que emergem das performances cênicas marcadas pelas guerras e matanças. Expressão da cultura popular festiva e urbana de nossos dias, as Tribos de Índios atualizam essa imagem que vem "de outros carnavais", mesclando expressões espetaculares às suas apresentações, atraindo e fascinando seus performers, assim como o seu público. Caberá ainda revelar por que e contra quem eles contendam.

Retornando ao boi, agora no estado do Maranhão, trazemos uma original abordagem de Lady Selma Ferreira Albernaz em Eu não tenho paradeiro certo! Couro, boi e mióla no bumba meu boi maranhense. Arrematando o debate de gênero com festa junina e o boi, Albernaz revela como esta "brincadeira" operacionaliza o "riscado" social do cotidiano na festa, centrando sua análise em dois aspectos até então pouco problematizados na literatura antropológica sobre o assunto: seu couro e, sobretudo, seu miolo. A análise do couro do boi em sua dimensão mais simbólica (representando "a fortaleza" do coletivo) encontra seu sentido na definição de coisa, de T. Ingold (2012); o bordado que lhe constitui revela a percepção do bordador em sua relação com o mundo, expressando como seu pensamento "se liga ao mundo, indo além das operações abstratas da mente". Como na canção de Gilberto Gil (1983), onde a linha e o linho dialogam enquanto compõem um caminho no tecido, Albernaz reconhece a "porosidade do tecido": "as coisas de fato se fazem em fluxos e interconexões de materiais, dentre eles, nós humanos." A parte central do artigo é a discussão sobre os miolos do boi, parte interior do animal festivo que é habitada por uma pessoa (geralmente homem), revelando a vida do boi através de seus movimentos.

O miolo é bon à penser através do diálogo estimulante que Albernaz realiza entre seus dados de campo e as reflexões teóricas que sustentam seu argumento-chave: esta é parte socialmente invisibilizada porque a "vida do miolo não pode ser transposta para o boi, pois o boi é que está vivo, e não animado pelo miolo". Compreendemos então que a vida - e as coisas que dela decorrem como relações -, compõe uma trama "sem paradeiro certo", posto que nela também se inscrevem as agências (ORTNER, 1996), como evidencia a trajetória de Mauricéia: uma pioneira mióla que nos oferece um excepcional depoimento e reflexão acerca da vida como desafio, vontade e possibilidades.

Outro artigo traz à cena o debate sobre gênero no contexto da cidade de MossoróRN, no qual Francisco Janio Aires e Luiz Assunção apresentam Vaquejadas Contemporâneas: festa, cultura e negócio, refletindo sobre os aspectos comerciais envoltos nestas festas tão pouco conhecidas dos leitores, embora presentes em várias cidades do Brasil, e de forma muito intensa no Nordeste. Aires e Assunção revelam um universo de práticas e valores sociais que extrapolam 
o campo da festa propriamente dito e encontram ressonância no cotidiano de vaqueiros, donos de cavalos e visitantes de um parque urbano de vaquejadas. Partindo de uma análise bourdieusiana, os autores revelam como esta prática eminentemente rural em sua origem encontra na cidade um contexto privilegiado de consumo de bens e serviços, onde caminhões, roupas de grife e acessórios de montaria definem quem é quem no jogo social, conferindo um sentido suplementar de poder aos participantes dos concursos. Separados pela oposição "suor x perfume", vaqueiros e patrões disputam também um estilo de vida marcado pelas figuras do "boy vaqueiro" e do "playboy patrão", ambos associados a uma performance de masculinidade que envolve conquistas sexuais, consumo de bebidas alcoólicas, ostentação de dinheiro e de qualidades éticas compartilhadas com os visitantes e admiradores que frequentam o parque.

Num universo onde a moeda social é o cavalo (o "tesouro do patrão"), o feminino e a "bichinha" são a antítese do poder: "provar que é bom" define atitudes e valores de um modo de vida envolvendo reprodução de papéis sexuais e sociais com normas morais masculinas bastante hegemônicas. Dentre estas, se destacam a honestidade e a confiança, categorias sociais que atingem as relações de trabalho construídas por vínculos de pessoalidade pautados na palavra, aprofundando e reforçando simbolicamente as relações de dominação e dependência entre essas duas partes humanas centrais da festa: vaqueiros e patrões.

É o dono do cavalo quem decide a festa? De forma alegórica, essa pergunta conduz o leitor ao artigo Registros Sonoros do 'Folclore' de Alter do Chão: propriedade intelectual e patrimônio imaterial na festa do Çairé, de Luciana Carvalho. A partir de suas experiências críticas com pesquisas de campo antropológicas na realização de Inventários de Referencias Culturais para propostas de Registro de Patrimônio Imaterial, Luciana Carvalho apresenta algumas implicações e limites das ações associadas a esses inventários. No caso especifico da festa de Çairé de Alter do Chão, na Amazônia, ela nos oferece a narrativa histórica dessa festa que envolveu, em seus últimos desdobramentos, um processo de espetacularização e um desejo de patrimonialização, observado por ela "de perto e de dentro". Com seu relato, abordamos a complexidade de uma "situação social" - no sentido definido por Gluckman (2010) - envolvendo diferentes partícipes locais e não locais, como as comissões de Coordenação da Festa, os Botos, a Administração Distrital da cidade, seu Conselho Comunitário, festeiros, músicos, a Universidade Federal do Oeste do Pará e o Instituto do Patrimônio Histórico e Artístico (Iphan), todos participantes da confecção de um CD de músicas do Çairé que seria incorporado ao conjunto de materiais a ser apresentado juntamente ao registro do Inventário Nacional de Registros Culturais (INRC) da festa.

Surpreendentemente, o registro do CD assumiu os contornos de um conflito aberto, com foco na propriedade intelectual do patrimônio imaterial das músicas. Esse é o cerne da reflexão de Carvalho: além da propriedade moral que permanece protegida na lógica de registro do Iphan, como contemplar a autoria das execuções numa produção que extrapola o contexto da pesquisa de campo tradicional da Antropologia, e que o Termo de Autorização de Uso de 
Voz, Imagem e Informações proposto pelo Iphan considera de sua propriedade, antes mesmo de iniciado o registro? Em semelhante processo, seria possível equacionar as diferentes expectativas envolvidas, sem esquecer que cabe aos detentores, segundo o próprio Iphan, o direito de decidir sobre o destino de suas obras e produtos?

O alcance e as implicações na cultura popular das decisões políticas sobre patrimônios imateriais é o mote que conduz Carlos Henrique Cardoso e Fátima Tavares no artigo Patrimonialização do Carnaval em Maragogipe-BA: dinâmicas e ambiguidades da cultura. Manifestando uma necessária reflexão sobre os processos de patrimonialização das referências imateriais, Tavares e Cardoso discutem o caso particular dos Caretas do Carnaval da cidade de Maragogipe, registrado pelo Instituto do Patrimônio Artístico Cultural (IPAC), do Governo do Estado da Bahia, como patrimônio imaterial/ intangível, em 2009. O artigo centra-se nos aspectos históricos e políticos da festa, revelando como os Caretas assumiram progressivamente a "identidade" daquele município através do carnaval, chegando a representá-la atualmente como um emblema da cidade, tanto a nível local como nacional, e mesmo internacionalmente, por onde Maragogipe se faz apresentar e representar. O processo de "escolha" destes Caretas mascarados não é anódino: através da reconstituição de marcos temporais, e amparados em documentação/depoimentos locais, o artigo revela como as escolhas e decisões acerca desta patrimonialização foram conduzidos por grupos e pessoas situadas localmente em posições estratégicas, destacando-se a ação de secretários de turismo municipais e estaduais.

Evidenciam-se então as consequências dessas políticas que potencializam a dinâmica das transformações operadas na festa, tanto "por dentro", como "para fora": quais as tensões e os efeitos desse processo, e em que medida elas ultrapassam as intenções e os objetivos iniciais dos seus idealizadores? Como situar o patrimônio numa festa onde tradição e mudança dialogam intensamente, produzindo um espetáculo cada dia mais elitizado, distante da experiência de carnaval igualitária (DAMATTA, 1983) dos detentores, e cada dia mais associado ao "mercado e ao entretenimento", como destacava Arantes (2004)? Quais “vazamentos” de sentido conduziram à surpreendente onipresença das máscaras de Veneza na estética local de uma antiga tradição feita de sacos de farinha e cimento?

O artigo Santo Antonio de Aracaju: etnografia e narrativas sobre um lugar, de Ulisses Neves Rafael, fecha nosso dossiê, dialogando com o artigo precedente, conquanto ambos discutem imagens e representações de setores dominantes sobre as cidades e suas festas populares, e como estas têm seus sentidos transformados pela intensa comunicação entre os diferentes protagonistas da cultura. Ulisses Rafael revela aqui estas vigorosas e duradouras relações, seguindo a pista de uma celebração central do calendário religioso e festivo da cidade de Aracaju-SE: a Trezena de Santo Antônio. Ele mostra como a própria identidade daquela cidade, inicialmente identificada a pântanos e mangues, vai assumindo uma imagem mais confiante e otimista à medida em que vai conquistando um arruamento contíguo a seus domínios imediatos, o Povoado de Santo Antônio. 
Integrando-o em seu conjunto imagético, Aracaju associa sua memória à daquele lugar, superando sua constituição recente e seu relativo encobrimento histórico em relação a São Cristóvão - capital do estado até 1855. Enquanto reforça suas fronteiras simbólicas com os bairros circunvizinhos de forte composição operária, o Santo Antônio vai se fortalecendo enquanto símbolo e estabelecendo uma relação diferenciada com a cidade de Aracaju, cujos moradores sobem alegremente as suas ladeiras em busca de reminiscências e de um passado mais positivo e significativo. São as narrativas de memorialistas, poetas, romancistas, cronistas, historiadores, geógrafos e outros pesquisadores locais que fornecem a nosso autor o material central dessa construção imagética, frequentemente revelando uma cidade esfacelada que visa garantir para si um espaço de tradição.

Na observação direta da Trezena que Rafael realizou em sua pesquisa de campo, percebemos como essa celebração mantém uma forte relação com as tradições descritas nas obras visitadas, entretecendo uma malha de forte apelo afetivo e mnemônico em seus participantes. Hoje ela ocorre numa grande diversidade de espaços e em experiências variáveis segundo classes, gêneros e gerações, combinando o fervor religioso, a sociabilidade amical e afetiva, e mesmo situações de jocosidade em relação ao santo. Sem estabelecer um mundo ao contrário e longe de constituir um "rito sem dono", a Trezena e sua procissão final também parecem escapar ao "modelo dos eventos sociais marcados exclusivamente pela motivação do divino e realizados sob a égide da Igreja", oferecendo assim uma possibilidade privilegiada de percepção da cidade através de suas elaborações imagéticas e sentimentais.

Temos, enfim, aqui reunidos, um conjunto significativo de trabalhos produzidos sob a marca da inquietude e da provocação. O esforço coletivo empreendido na organização deste dossiê envolveu a generosidade e o comprometimento dos colaboradores, a satisfação incondicional dos organizadores e a recepção sempre calorosa dos editores dessa revista. Nosso desejo é que este mesmo sentimento de contentamento provocado pelo encontro aqui estabelecido possa impregnar o leitor quando da leitura das estimulantes reflexões aqui contidas, aprofundando sua compreensão sobre as festas, enquanto espetáculos e patrimônios culturais.

\section{Bibliografia}

ANDRADE, Mário de. Danças dramáticas do Brasil. Brasília: Editora Itatiaia em convênio com o Instituto Nacional do Livro, Fundação Nacional Pró-Memória, 1982.

ARANTES, Antônio. O patrimônio imaterial e a sustentabilidade de sua salvaguarda. Resgate, Campinas, v. 12, n. 1, p. 11-18, 2004.

BATAILLE, George. A parte maldita precedida de “A noção de dispêndio”. Belo Horizonte: Autêntica Editora, 2013.

BAUDRILLARD, Jean. A ilusão do fim ou a greve dos acontecimentos. Lisboa: Terra Rara, 1992.

CAILLOIS, Roger. O sagrado de transgressão. Teoria da festa. Outra travessia, Florianópolis, n. 19, p. 15-56, 2015. 
DURKHEIM, Émile. As formas elementares da vida religiosa. São Paulo: Martins Fontes, 1996.

DAMATTA, Roberto. Carnavais, malandros e heróis. Para uma sociologia do dilema brasileiro. Rio de Janeiro: Zahar Editores, 1983.

DUVIGNAUD, Jean. Festas e civilizações. Fortaleza : UFC, 1983.

FRAZER, James. O Ramo de Ouro. Rio de Janeiro: Editora Guanabara Koogan. 1982.

GIL, Gilberto. A linha e o linho. In: Extra. Rio de JaneiroGilberto Gil:, Warner Music, 1983. 1 CD (ca. 40 min. 50 s.). Faixa 4 (3 min. 8 s.).

GLUCKMAN, Max. Análise de uma situação social na Zululândia moderna. In: FELDMAN- BIANCO, Bela (Org.). A Antropologia das sociedades contemporâneas: métodos. São Paulo: Editora Unesp, 2010. p. 227-344.

INGOLD, Tim. Trazendo as coisas de volta à vida: emaranhados criativos num mundo de materiais. Horizontes antropológicos, Porto Alegre, v. 18, n. 37, p. 25-44, jun. 2012.

LEACH, Edmund. Cultura e Comunicação: a lógica pela qual os símbolos estão ligados. Rio de Janeiro: Zahar Editores, 1978.

MELO MORAIS FILHO, Alexandre José de. Festas e Tradições Populares no Brasil. Itatiaia: Edusp, Belo Horizonte: São Paulo,1979.

MAUSS, Marcel. Ensaio sobre a Dádiva. Forma e razão da troca nas sociedades arcaicas. In: Sociologia e Antropologia. São Paulo: Edusp, 1974Cosac \& Naify, 2013. p. 1-184183-314. p. 1-184.

ORTNER, Sherry. Making Gender: The Politics and Erotics of Culture. Boston: Beacon Press, 1996.

TURNER, Victor. O processo ritual: estrutura e anti-estrutura. Petrópolis: Ed. Vozes, 1974.

Recebido em: 18/01/2019

Aceito em: 18/01/2019 